\title{
Symbiotic modeling
}

Linguistic anthropology and the promise of chiasmus

Jamin Pelkey

Ryerson University

Department of Languages

Toronto, ON M5B 2K3

Canada

jpelkey@ryerson.ca

Pre-print Copy, Published:

2016. Reviews in Anthropology 45(1). 22-50. http://dx.doi.org/10.1080/00938157.2016.1142294

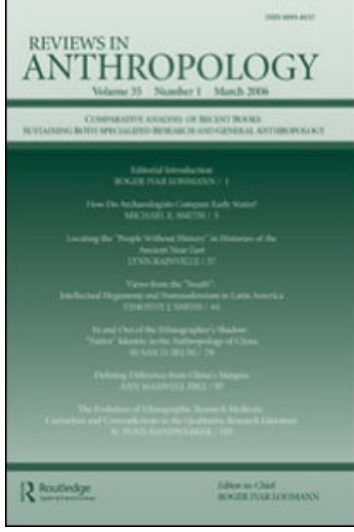




\title{
Symbiotic modeling
}

\section{Linguistic anthropology and the promise of chiasmus}

Jamin Pelkey

Enfield, N. J., Paul Kockelman, and Jack Sidnell, eds. 2014. The Cambridge Handbook of Linguistic Anthropology. Cambridge: Cambridge University Press.

Strecker, Ivo, and Stephen Tyler, eds. 2009. Culture and Rhetoric. Studies in Rhetoric and Culture 1.

Oxford: Berghahn.

Wiseman, Boris, and Anthony Paul, eds. 2014. Chiasmus and Culture. Studies in Rhetoric and Culture 6.

Oxford: Berghahn.

\begin{abstract}
Reflexive observations and observations of reflexivity: such agendas are by now standard practice in anthropology. Dynamic feedback loops between self and other, cause and effect, represented and representamen may no longer seem surprising; but, in spite of our enhanced awareness, little deliberate attention is devoted to modeling or grounding such phenomena. Attending to both linguistic and extra-linguistic modalities of chiasmus (the X figure), a group of anthropologists has recently embraced this challenge. Applied to contemporary problems in linguistic anthropology, chiasmus functions to highlight and enhance relationships of interdependence or symbiosis between contraries, including anthropology's four fields, the nature of human being and facets of being human.
\end{abstract}

KEYWORDS Anthropological linguistics; chiasmus; culture; interdependence; modeling

Linguistic anthropology is opening up. Practitioners are forging connections across diverse disciplines and technologies, exposing narrowly held (and often highly polarized) language ideologies to extra-linguistic insight and critical scrutiny, strengthening ties with field linguistics, and retrieving valuable practices once surrendered to history (see Reyes 2014, Enfield et al. 2014, Graber 2015). Out of this foment, an international group of linguist-anthropologists (or anthropologically sensitive linguists) have produced a landmark handbook to rally the field. Edited by N. J. Enfield, Paul Kockelman, and Jack Sidnell, The Cambridge Handbook of Linguistic Anthropology is (in my estimation) designed not so much to expand the borders of the discipline as to make them more porous, particularly toward cognitive insights, but also toward historical-comparative approaches, evolutionary approaches, more robust ontological and philosophical grounding, and stronger integration with anthropology's other three fields. 
The overarching nature of relationships proposed in the volume is less content with one-way development than with two-way integration: favoring relations of interdependence or mutual reciprocity. And yet, for all of the intimations toward "reflexivity" that can be found in the handbook, and in the discipline more generally, little reflexive attention is devoted to the actual linguistic (and extra-linguistic) structure of reflexivity itself. Fortunately, this attention deficit cannot be said to characterize all corners of the field.

Working under the aegis of the Rhetoric Culture Project, another group of linguistic and sociocultural anthropologists has also been energized during this period of foment. Drawing on a rich network of cross-disciplinary connections with literary theorists, rhetoricians, and philosophers, the group seeks to uncover ways in which processes of reflexivity in linguistic and extra-linguistic contexts exist along a continuum from forced stasis to living symbiosis. In order to unlock such insights, the movement has converged on a specific figure of speech known as chiasmus.

Chiasmus (also discussed as the $\mathrm{X}$ figure and often formally rendered A:B:: $\left.\mathrm{B}^{\prime}: \mathrm{A}^{\prime}\right)$ can be described as the parallel, or (a)symmetrical, inversion of two or more terms framed as antithetical pairs, being held in something of a mirror image relation in order to suggest processes of tension, reversal, or exchange. Consider, for instance, Canadian Prime Minister Justin Trudeau's novel assertion in his recent acceptance speech (October 19, 2015): "If Canadians are to trust their government, their government needs to trust Canadians." As Rhetoric Culture practitioners clarify, the figure should be approached not simply as a decorative flourish, nor merely as a symmetrically reversible form, but as a figure of human thought-a cross-cultural "creative principle" (Wiseman 2009:92). The Rhetoric Culture movement itself grows out of a "highly reflexive attitude" (Oesterreich 2009:57), deliberately reflecting not only on other ways of writing, speaking, and thinking, but also on one's own (and one's groups') ways of doing so. This is important since "anthropology cannot be separated from the discourses that vehicle it and the rhetorical figures they contain" (Wiseman 2009:86).

In what follows, I bring the Cambridge handbook into dialogue with two recent volumes from the Rhetoric Culture movement to show how the very language and linguistic structures employed by various Enfield and colleagues (2014) contributors, to discuss important problems and possibilities at the heart of the field, actually rely on formal and semantic dynamics of chiasmus: rhetorical practices that are not explicitly discussed in the collection itself. Contributor R. M. W. Dixon argues (2014:29), for instance, that "any decent linguist must invoke a fair dose of anthropology, and that in order to achieve significant results, an anthropologist should harness the essentials of linguistics" (underline formatting mine, also below). The antisymmetrical $A: B:: B^{\prime}: A^{\prime}$ patterning in this statement provides a kind of structural congruence or model of the interdependent relations it proposes. As contributors 
to the Rhetoric Culture Project illustrate, careful thinkers in many domains, including luminary anthropologists such as Claude Lévi-Strauss, have (at least implicitly) shown the figure to be at work far beyond speech and writing, including the heart of social systems and the practice of ethnography itself.

In the end, though, I will argue not only that linguistic anthropology should embrace the Rhetoric Culture movement, but also suggest ways in which the Rhetoric Culture movement can further benefit from contemporary perspectives in linguistic anthropology. Prominently included are ways in which Enfield and colleagues (2014) contributors actively seek to forge interdependent dialogues between widely divergent perspectives, including anthropology's biological and archaeological fields. Ultimately, relationships of interdependence or symbiosis typified in chiasmus patterning are relevant to any domain in which oppositions or paradoxes are in need of reconciliation: a description that may well apply to every domain of human inquiry.

\section{A new vision for linguistic anthropology}

As suggested above, Enfield and colleagues' (2014) Handbook of Linguistic Anthropology casts a fresh vision for the field by forging new relationships, strengthening old ones, and retrieving others long lost. In the volume introduction this overall contribution is framed as a "broad" view for the field, in contrast to its supposedly "narrow" and "well-institutionalized" counterpart ensconced in the American Anthropological tradition (2014:2-6). It should be noted that this move is in itself a rather overt rhetorical strategy with its own curious, implicit designs. Whether this broad-versus-narrow framing is actually necessary and warranted or largely an unnecessary distraction is an important question, one reserved primarily for a later section. Here I outline the range of relations-new, old, and retrieved-that are enhanced in the handbook, and then I draw attention to a distinct signal: evidence of a general semiotic grounding that emerges from the chapters.

New agendas proposed in the handbook for linguistic anthropology primarily involve philosophical, socio-cognitive, and psycho-linguistic relations. These include Enfield's (2014a) own helpful discursus on the so-called item-system distinction and his detailed summary of the "causal dynamics of language" (2014b). In different ways, each of these treatments provides insight into both the psychology and the ontology of language while admirably managing to resist the pull of age-old nativist-behaviorist and rationalist-relativist dichotomies (e.g., language as innate, abstracted grammatical competence vs. language as socially motivated speech performance). In certain respects, Enfield affirms both sides of such divides; but ultimately (and more importantly) moves the dialogue beyond the old binary frames.

Sidnell's (2014) discussion of "the architecture of intersubjectivity" and Sidnell and Enfield's (2014) discussion of "the ontology of action, in 
interaction" are two further contributions that draw heavily on the psychology of language and the study of human cognition. A further new direction includes Levinson's (2014) proposed links with biolinguistics, exploring possible relationships between cultural, linguistic, and biological evolution and their relevance for linguistic anthropology. Finally, Kockelman issues a prospectus for a linguistic anthropology of human-computer interaction focused on "automatized languages": languages that are both networked and formatted (2014:726). All such innovations may be identified as instances of linguistic anthropology rising to meet "the cognitive challenge" recently articulated by Maurice Bloch (2012).

The collection also serves to strengthen old relations that have long been staples of the field. Dixon's (2014) masterful summary of language structure and linguistic description reaffirms the importance of field linguistics in the anthropology of language. Relationships with sociolinguistics are maintained and updated by Penelope Eckert (2014), as are the status of language endangerment and language maintenance (Rice 2014). Relationships with co-speech gesture and sign language are affirmed and expanded by Goldin-Meadow (2014) and Sandler et al. (2014), respectively. The status of connections with language acquisition (Brown and Gaskins 2014) and the nature of social interaction (e.g., Dingemanse and Floyd 2014; Rumsey 2014; Muehlmann 2014) are also treated admirably in the volume, as are the status of ritual, rhetoric, and poetics (Tavárez 2014; Bate 2014; Fleming and Lempert 2014). Finally, ongoing relationships with media studies (Gershon and Manning 2014) and the status of critical theory in the field (Kockelman 2014) are provided with particularly cogent treatments.

Other affirmations of linguistic anthropology's longstanding commitments include expressions of vital integration with sister fields in anthropology: socio-cultural, biological, and archaeological dimensions in particular. In addition to chapters on ritual and social organization mentioned above, Rupert Stasch (2014) provides the most overt and detailed treatment of inter-relationships with socio-cultural anthropology, showing how paying attention to signs of resemblance and signs of direct causation (iconicity and indexicality, respectively) shared between the "linguistic and extralinguistic layers of human lives" may help us see that they are "probably more interdependent and more like each other than current writing of linguistic and sociocultural anthropologists generally gets across" (2014:632-633). Vital connections with biological anthropology are covered by Stephen C. Levinson and Dan Dediu. Levinson draws attention to relationships between "both fields of language evolution": "the evolution of biological capacity for language and the cultural elaboration of languages" (2014:321), while Dediu (2014) focuses on relationships between genetic diversity and linguistic diversity. Relationships with archaeology are updated in Roger M. Blench, who asserts that combining "archaeological results with linguistic reconstruction 
and nuanced understanding of social process derived from ethnography allows us to evolve a richer model of prehistory" (2014:661).

As some of the above connections may suggest, the handbook also serves to retrieve aspects of the anthropology of language that have long been neglected in the field, in spite of their arguably indispensable status. Chief among these is the affirmation of historical-comparative methods and diachronic insights scattered across the volume (see Faudree and Hansen 2014; Levinson 2014; Enfield 2014b; Blench 2014). Another example involves more careful consideration of the nature of language universals and linguistic diversity (Bickel 2014). Conversely, some key hallmarks of the field are curiously demoted or de-emphasized in the collection, including discussions of language and ideology, otherization, semantic domains, cross-cultural categorization, semantic mapping, and kinship relations-some of which are excised altogether.

Finally, it is worth noting that out of 29 contributions published in the handbook, no fewer than 14 make explicit use of models and concepts drawn from a general semiotic that traces its lineage back to C. S. Peirce. At least eight of these contributions reference Peirce directly (see Silverstein 2014; Faudree and Hansen 2014; Rumsey 2014: Bate 2014; Gershon and Manning 2014; Kockelman 2014a; Stasch 2014; Kockelman 2014b). Others make use of Peircean concepts such as "iconicity" and "interpretant" without registering their origin (see e.g., Eckert 2014:653; Sidnell and Enfield 2014:423). Still other contributions draw evident inspiration from Peircean ideas while simultaneously masking origins and replacing parlance. The most striking example of this would appear to be Enfield's (2014a) extended discussion of an "item/ system" distinction for language ontology, which has clear precedence in Peirce's token-type contrast. Acknowledging this source would have the added benefit of better facilitating integration (and calibration) with the role this pair plays in its larger semiotic system of origin, where they function as "iconic sinsigns" and "iconic legisigns" respectively (see Peirce 1904). Recognizing the more general model might also provide the proposal with more weight and staying power.

Notably, this final feature of the volume can be classified as neither innovation, nor entrenchment, nor retrieval. Openness to a general semiotic is recently emergent as a characteristic of the field at large (see again Reyes 2014; Graber 2015). This is a key point for multiple reasons: First, because it calls into question the "narrow view/broad view" trope conjured up in the handbook introduction to bear so much rhetorical weight. It appears, instead, that an openness to more general theoretical models is actually a quality already present in the field; second, because a general (Peircederivative) semiotic is radically interconnected. Rooted in phenomenological categories of experience, it elaborates a system of sign classes and sign functions in which meaning and meaning-making activities that are evident 
in cultural and linguistic sign processes can be situated within pre-linguistic and extra-linguistic ecologies of sign relations, all of which work together in human communication. Third, because it is evolutionary-a processoriented system necessitating degrees of continuity between human and other animal communication systems and between natural and cultural processes of signification. Finally, as I propose further below, this orientation could be of particular use to the development of theoretical and ontological grounding for various ideas and findings now emerging within the Rhetoric Culture Project.

\section{The Rhetoric Culture Project}

The Rhetoric Culture Project grew out of a long-standing dialogue initiated in the early 1980s between Ivo Strecker, a socio-cultural anthropologist (professor emeritus, Johannes Gutenberg University of Mainz), and Stephen Tyler, a linguistic anthropologist (professor emeritus, Rice University). The inaugural bid to involve other scholars in their developing conversation occurred in 1998 through the first workshop on "Rhetoric Culture Theory" at a social anthropology conference in Germany, after which the working group expanded to include rhetoricians, philosophers, literary critics, historians, and psychiatrists, in addition to many other cultural and linguistic anthropologists. The movement developed into a series of dedicated conferences on the theme during 2001 to 2005, along with a vital book series that continues to generate new volumes ten years later, including the following seven titles to date:

1. Strecker and Tyler's (2009) Culture and Rhetoric

2. Carrithers' (2009) Culture, Rhetoric and the Vicissitudes of Life

3. Gudeman's (2009) Economic Persuasions

4. Meyer and Girke's (2011) The Rhetorical Emergence of Culture

5. Strecker and Verne's (2013) Astonishment and Evocation

6. Wiseman and Paul's (2014) Chiasmus and Culture

7. Hariman and Cintron's (2015) Culture, Catastrophe and Rhetoric

Volumes 1 and 6 are of special interest for the purposes of this essayVolume 6 in particular-but first consider the inaugural collection for more adequate context. The Culture and Rhetoric volume (Strecker and Tyler 2009) is published on the premise that a reassessment of rhetoric "as an allembracing study of discourse and culture" (Tyler and Strecker 2009:21) is much needed in the contemporary milieu. As with the volume, so with the movement: both aim to draw attention to overlooked aspects of speech and ritual, along with other creative and imaginative practices, featured in ordinary social life across cultures. The movement aims to rethink and relocate the concept of culture within rhetoric, "bringing rhetoric and anthropology closer to each other than they have even been before" (2009:1). 
According to Alan Rumsey, however, this move must also be understood as a call for "a radical transformation in what we mean by the rhetorical" (2009:117). Conversely, it can also be thought of as "the restoration of rhetoric's efficacy" according to Philippe-Joseph Salazar (2009:163); since, as Peter L. Oesterreich affirms, the movement takes seriously "the task of promoting a process of transcultural understanding" between diverse worldviews and cultures, while simultaneously standing "against all dogmatisms" (2009:57).

According to Tyler and Strecker themselves, the movement pivots on the recognition that a rhetoric of socialization functions at both inner and outer levels, comprising both an object of study and an instrument of practice (or persuasion), but also functions without illusions that Rhetoric Culture practitioners might function under a "higher order meta-discourse that we might call the theory of rhetoric" (2009:22). Rather, the group's focus is on the discovery, celebration, and critique of hidden dimensions of social discourse. The attention given to ordinary social practices in Rhetoric Culture Theory (RCT) is crucial, not only revealing rhetoric as something practiced in culture, but also revealing that cultural practices are themselves rhetorical. This overt chiasmus is explored at length by contributor Cannada Bartoli, who states that cultural rhetorics involve practical mastery of skills "acquired not through theoretical preparation or by following a project conceived in advance but through experience growing out of context and embedded in action" (2009:76).

The book "centers on chiasm and figuration" (Strecker and Tyler 2009:1), a set of themes that shape the respective halves of the volume's structure. Although chiasmus had long been recognized as a figure of special significance for the Rhetoric Culture movement (see Strecker and Tyler 2009:viii, 4 ), only two authors in the volume deal with the figure directly and at length: Boris Wiseman (2009) and Anthony Paul (2009). As a leading scholar and interpreter of Claude Lévi-Strauss, Wiseman $(2007,2009)$ draws attention to chiastic reversals and chiastic structures that typify many of Lévi-Strauss' major insights and contributions. Moving beyond classical treatments of chiasmus, Wiseman clarifies that he is not merely concerned with chiasmus as a stylistic device or figure of speech; he is intent, rather, on exploring chiasmus as "a pattern of thought, an organizing schema, a structure that determines, from behind the scenes, the form and content" of both Lévi-Straussian theories and "the process of anthropological understanding" more generally (2009:87).

Wiseman then goes on to show the chiasmus figure functioning at formative levels in many of Lévi-Strauss' major works. From relationships between painting and music across cultures (in Lévi-Strauss 1994) to relationships between hot and cold societies across time (1995), to relationships between games and rituals across events (1966), to relationships between self and other 
across cultures (1955, 1978, 1994), Wiseman finds a kind of "chiastic logic" in Lévi-Strauss. Far from merely organizing oppositional structures, chiasmus patterning functions as a hidden but dynamic figure of thought fulfilling a "reconciliatory function" in these works, serving "as a means of bridging seemingly insurmountable differences, of integrating heterogeneous elements" (Wiseman 2009:93).

In an earlier phase of life, however, Lévi-Strauss had ended his Tristes Tropiques (1955) in a tone less optimistic about the possibility of productive interchange between self and other. Wiseman identifies this early pattern of thought with a static, circular chiasmus, in which ethnographic understanding came to seem impossible to Lévi-Strauss due to his temporary assumption that the ethnographer's goal was to abolish differences between poles of "disjunction" and "conjunction," ultimately reducing other to self and self to other (Wiseman 2009:97-100). Harkin's 2010:29 appraisal of this notion (of self-other trading places) as a "tired trope" is especially relevant in this connection. Although a merely circular notion of chiastic thought would not come to mark Lévi-Strauss' work as a whole, Wiseman goes on to show in the remainder of the essay that the larger distinction involved is crucial for gaining a better understanding of the chiasmus figure.

The semantic typology of chiasmus is an important topic pioneered by Anthony Paul (1992, 2009), who probes why and how it is that chiasmus can be used in some instances as gratuitous verbal play, in other instances as anxiety-inducing paradoxes, and in still other instances (later explored in Paul 2014) as a means of discovering wholeness and meaning where none had seemed possible. To illustrate instances of the first two distinctions, Paul (2009) uses examples of chiasmus patterning in two of Shakespeare's plays, Hamlet and Macbeth, to explore this question.

He suggests that empty, fatuous uses of chiasmus in Hamlet, such as Polonius's statement "tis true, 'tis true, 'tis pity, /And pity 'tis 'tis true" (Act 2, Scene 2), are congruent with the trivial nature of relationships among "the Danish court, the play's metaphor for the world,... a place of hollow forms, doubleness, insincere smiling appearances" (Paul 2009:107). This stands in sharp contrast to feelings evoked by the form in Macbeth, evident in lines such as "fair is foul and foul is fair," a doubly antithetical contradiction that also functions as a microcosm of the broader ecology of meaning in the play: viz., "a trap-mental, moral and existential" (2009:110). In the play as in social life, unless we are able to identify such double-bind patterns, we remain with Macbeth, locked into paralyzing habits conditioned by contradictory social codes (as explored in Bateson et al. 1956). Paying attention to chiasmus patterning, then, can help us distinguish between social situations in which we are masters of rhetoric and those in which rhetoric masters us (Paul 2009: 105). 


\section{The master figure}

In the final chapter of Strecker and Tyler's (2009) collection, Robert Hariman promotes allegory as a candidate for the Rhetoric Culture movement's "master trope" (2009:225-227). While this proposal may still have merit, it has not yet been embraced by the Rhetoric Culture Project more generally. Chiasmus, on the other hand, has emerged as the master figure of the movement. Due to founding assumptions of a reciprocal chiastic relation between rhetoric and culture, the group's affinity for chiasmus modeling seems to have been foreshadowed from the movement's inception (see Tyler and Strecker 2009:4; Paul and Wiseman 2014: 6-8).

The sixth volume in the Rhetoric Culture series (Wiseman and Paul 2014) is dedicated to exploring the chiasmus figure as "a deep structure of life experience" (Paul 2014:42), opening up new vistas for future research, establishing foundational insights for the development of chiasmus studies across the disciplines, and demonstrating the figure's timeliness and untapped potential. Paul and Wiseman's introduction to the volume further situates the chiasmus figure in the history of ideas and expands on earlier arguments that chiasmus is useful for both the production and discovery of meaning (Strecker and Tyler 2009:9), given that it is a pattern both of thought and for thought: "a dialectical tool" (Paul and Wiseman 2014:3), "a process of change" (2014:5), a dynamic pattern that is both "diagram and force, system and movement" and a "powerful instrument for opposing dogmatism and time-honoured nonsense" (2014:5). As Strecker notes, a primary motivation in producing the volume is to continue the work of elevating chiasmus to the status of better-known rhetorical figures and tropes, such as irony and metaphor (2014:69-70; see Lissner 2007; Pelkey 2013c, for earlier work in this vein).

Among the many benefits of paying closer attention to chiasmus patterning is the promise it shows as a practical dialectic: a tool for dealing with binary contradictions and other oppositions. Chiasmus can be used both to vividly frame the contradiction or rupture between some set of oppositions and simultaneously to bring these differences into dialogue. Furthermore, reflexivity and chiasmus go hand-in-hand. In the words of Paul and Wiseman (2014:2) "the spirit of chiastic inversion [allows] the questioner to be questioned by his own object of attention." Multiple authors in the volume suggest that the ultimate purpose of chiastic modeling is to move beyond mere Hegelian holism, or bland synthesis between thesis and antithesis that threatens to destroy individual uniqueness (see Tyler 2014; Paul 2014:40-42; Wiseman 2014:226). Instead, chiasmus functions simultaneously to both join and split such phenomena (Paul and Wiseman 2014:11): "to embrace oppositions and transcend contradictions" (Paul 2014:41).

In more complex instances, chiasmus can function as a "tool for analogical transposition" (Wiseman 2014:233), useful for problem solving, whether 
deliberate or unwitting, through modeling problematic or complementary relationships. One such instance is the "double-twist" chiasmus pattern found in Lévi-Strauss' (1958) "canonical formula" for the deep structure of myth, "a logical model capable of overcoming a contradiction" (1958:264, cited in Wiseman 2014:226). Beyond the realm of myth, chiastic modeling is shown to be useful for carrying out empirical mixed-methods research in Pelkey (2011). Other authors in the collection draw attention to mundane uses of chiasmus through history, for coping with and overcoming everything from anxiety to impotence (see, e.g., Hariman 2014:60, Usher 2014:152). In this mode, chiasmus patterning corresponds with what Marvin Shaw has entitled "the paradox of intention" (1988). In this mode, chiasmus is also something of a hermeneutic key or prism (Paul and Wiseman 2014: 7, 12), enabling us to identify, perform, and better understand reversals in perspective or behavior (see Bollig 2014:172, Lewis 2014:188, 199, 212) and better enabling us "to live in harmony" (Paul 2014:42) with people, ideas, and other entities that are "at once diverse and in relationship" (2014:15).

Naturally, approaching chiasmus as a figure of thought or a dialectical tool ranges far beyond traditional treatments of the form as little more than decorative or aphoristic flourish (e.g., "eat to live; don't live to eat"). Such treatments tend to stop at the level of basic, surface syntax. By contrast, far more attention is devoted in the Wiseman and Paul (2014) volume to modes of chiastic patterning that are much "more subtle" (Bollig 2014:181): chiasmi operating at conceptual levels heavily reliant on tacit cognition, or "structures that are essentially unconscious" (Wiseman 2014: 225). Discussed as the exploration of "chiasmus phenomena" (Lewis 2014:188, attrib. to Ivo Strecker) and "chiasmus events" (2014:211), this mode of chiasmus patterning includes discussions of grammatical chiasmus (Bollig 2014:169; Usher 2014:156, 158; Wiseman 2014:229), thematic chiasmus (Bollig 2014:163, $164,166)$ phonetic chiasmus (2014:163) and ritual chiasmus-both in "oratory" and "ostensive" performances (Lewis 2014). Wiseman's identification of chiasmus patterns in the generative deep structure of mythology $(2014: 220,223,224)$, which are in turn analogous to the Klein group and Quaternion group in mathematics $(2014: 236,238)$ also factor in here. The contrast with traditional treatments is so dramatic, in fact, that knowing quite how to frame distinctions and relations between differing levels or phases of chiasmus patterning remains unclear, especially between volume contributors. Bollig (2014:182), for instance, frames the basic distinction as "chiastic thought" versus "chiasmus proper," suggesting tacitly that surface syntax is the most basic mode of chiasmus. Naturally, from a folk perspective this may make sense, but from a grounding perspective it is problematic. Nevertheless, it highlights the kinds of challenges facing chiasmus studies in the immediate future. Much more discussion and inquiry is needed on grounding models and mechanisms, a point I discuss further in the next section. 
Typologies of chiasmus are also needed; and to this end, Paul's (2014) thoughtful and richly illustrated proposal of four basic categories of chiasmus patterning (cross, mirror, circle, spiral) is likely to serve as a touchstone for further development across the decades to come.

A further reason for paying closer attention to the chiasmus figure lies in "its potential to shatter expectations and conventions (and establish new ones)" (Strecker 2014). The figure can assist in identifying false or misleading dichotomies (see Paul 2014:40-41; Hariman 2014:50, 57-59), enabling us to overcome or cope with the influences enforced by socially constructed prison houses of language and thought (see Hariman 2014:60). This, in turn, can enable us to supersede familiar categories (Paul 2014:38). It is in this way that chiasmus is useful for opposing dogmatism (Paul 2014:42), helping us wake up to ideological traps so that we can find a way out. Because of this, chiasmus is discussed as a figure that is potentially healing or liberating (see Usher 2014:157, 158; Bollig 2014:164, 169; Wiseman 2014:233)—even transforming (Strecker 2014:87) and regenerating (Wiseman 2014: 225). According to Strecker (2014:87), however, such benefits can only result from working through less pleasant experiences of surprise or shattered expectations. This facet of chiasmus is discussed as a "(dis)organizing principle" (Usher 2014:157) and as a "destabilization agent" (Bollig 2014:164). From this perspective, to the degree that chiasmus patterning is structural, the structure itself is unstable (2014:173). Because of this, chiasmus can easily be experienced as a face-threatening act, an unwelcome, asocial intrusion (Strecker 2014:73, 78-80, 85). In this connection, the figure may also function as "a basic operation of censorship in the psyche" (Vanier 2014:143), and can even be construed as dangerous in some cultures (Lewis 2014:188, 195, 197).

The reverberation and confusion that results from chiasmus in this phase is similar to what some have identified with experiences of novel metaphor (see Strecker 2014:75). Other aspects of experience also appear to overlap between novel metaphor and chiasmus, such as juxtaposition, semantic tension, and interaction (2014:74, 81). In fact, as I have argued elsewhere (Pelkey 2013c), chiasmus patterns-in-process may well prove to be involved in or identical with what theorists in cognitive semantics now identify as "conceptual blending" (Faucconier and Turner 2002). A few contributors to Wiseman and Paul (2014) come close to suggesting such relations in discussions of synesthetic experience, which are identified as intrinsically chiastic (see Paul and Wiseman 2014:15; Strecker 2014:81). In chiastic modeling, the "place of mixing and merging" (Wiseman 2014:224) that results from blending two extremes can be identified as the creation of a "third term." This distinction is crucial for moving discussions of chiasmus beyond assumptions of binary modeling that have tended to mark the topic (as referenced in Bollig 2014:167; Vanier 2014:146, see also detailed discussion in Pelkey 2013c). 
The significance of a third term that emerges from oppositional contrasts in chiasmus patterning is discussed by several volume contributors (Paul 2014; Strecker 2014; Hariman 2014; Wiseman 2014). These discussions go back to Wiseman's (2009) essay on ethnographic chiasmus in Lévi-Strauss introduced above. What keeps the anthropologist from being either cut off from the other or absorbed into the other is a third, mediating position between self and other (see Wiseman 2009:99), a role that can be filled by language learning, which results inevitably in a kind of interlanguage (see also 2009:100-101). Thus, the emergent "third term" in chiasmus modeling serves an "osmotic function" (Bollig 2014:172), opening up a blended space of reciprocity and new possibility.

\section{Grounding problems}

The Rhetoric Culture Project's new vision for the chiasmus figure is ambitious and promising but could benefit from more adequate grounding. The same might be said regarding Enfield et al.'s new vision for linguistic anthropology. Naturally, in some sense grounding problems come with the territory. As Harkin has pointed out, "anthropology has never been entirely clear or confident about its epistemological standing" (2010:27). But, setting aside peevish complaints on problems insoluble, my wish here is simply to suggest a number of immediate ways each project might benefit from the relatively more grounded strengths of the other, in different domains. Furthermore, both might benefit from grounding insights not yet adequately integrated that are, nonetheless, readily available elsewhere.

First, it is worth noting three ways the Rhetoric Culture movement's critical vision is reflexively grounded that may be of use to Enfield et al.'s project: (1) the movement's abiding search for congruence between theoretical architecture and cross-cultural patterning, (2) its more open (vs. brashly imperialist or merely contrarian) approach to institutionalized theory and practice, and (3) its more reflexive awareness of theory-internal language usage. These issues I reserve for discussion in the next section. Promising aspects of Enfield et al.'s new vision that should be of interest to the Rhetoric Culture Project for ontological and empirical grounding include the following: (1) a strong orientation toward a more general semiotic, (2) an active interest in contributions to and from evolutionary theory, and (3) more active attempts to integrate with all four fields of anthropology (beyond the linguistic and sociocultural). The latter two strengths were discussed above. Here I discuss the promise of a more general semiotic along with three further grounding perspectives that might be better integrated by both projects: (1) the developing notion of diagrammatization in linguistic semiotics, (2) insights from the Cultural Symmetry movement, and (3) embodied phenomenological approaches to human cognition. 
As discussed above, the general semiotic affirmed in the aggregate by Enfield et al. (2014) contributors is an approach to meaning that spans nature and culture, an approach in which ecologies of signifying systems are constantly evolving and continuous between widely diverse modalities such as body-mind, physical-imaginary, conscious-subconscious, self-other, and human-animal divides. This semiotic is rooted in phenomenology as much as in logic, in mathematics as much as in poetics. What the Rhetoric Culture Project might gain from embracing this general semiotic for its own ends is the benefit of moving away from the limiting solipsistic consequences of glottocentric presuppositions. As John Deely has shown (e.g., 2001, 2012), a worldview in which linguistic ideas are accepted as primary is also a worldview in which the individual or social collective is cut off from the broader universe. Such an approach is also (whether or not it sets out to be either), ultimately, an anti-evolutionary perspective.

This is not to suggest that the Rhetoric Culture Project is somehow antagonistic toward semiotic theory. As Salazar notes, "Anthropology, as a central task, argues about social facts as social signs" (2009:157); rather, the movement's founders work under the assumption that semiotics is to be subsumed under a more general theory of rhetoric, arguing that the “'codes', 'systems', and 'structures' analyzed by semiotics" are to be explained as part of our "rhetorical genius" since we are the ones who have invented them (Tyler and Strecker 2009:1). The movement's founders also work under the assumption that questions of meaning exclude qualities of feeling (2009:23). Both assumptions about signs and meanings can be traced back to glottocentric theories of semiotics, which hold linguistic codes and concepts to be the primary objects of thought and construe sign-object relations as binary (or deterministic) and arbitrary. This approach to sign relations cannot properly be described as a "general semiotic" since it ceases to hold relevance beyond the mind of any given individual or social collective.

Rhetoric Culture practitioners also appear to be glottocentric in their own presuppositions. Wiseman asserts, for instance, that "all social and cultural practices are linguistically mediated" (2009:85). The movement's founders claim to follow Humboldt in asserting that "reason is inseparable from language; thought inseparable from speech" (Tyler and Strecker 2009:25). If so, and if language is rhetorically generated, this line of reasoning would make rhetoric king of all human affairs-quite a happy consequence, perhaps, for any rhetorician. To give up on this view of language would mean that "Rhetoric" along with all "rhetorics" must be approached not as regnant over all else but as situated along with all else. The benefits of this demotion, however, would be immediate. The movement would not only find better congruence between philosophical presuppositions and their master figure, chiasmus (as I explore further below), but practitioners would also be able 
to solve basic problems generated by their own presuppositions, such as the contradictory assertion of non-human animal rhetoric (Maranda 2009:209-210) pitted against claims of "homo-rhetoricus" (Oesterreich 2009) found in their own inaugural volume.

A stronger grounding in general semiotics would be beneficial in many ways for contributors to the Enfield et al. collection as well, prominently including Enfield's own thoughtful explorations in search of better ontological-philosophical grounding for language and linguistic modeling. Finding more adequate semiotic grounding might at least inspire more confidence than the present use of quirky (trivializing?) mnemonic acronyms like Enfield's "four-stroke engine model" for understanding cultural transmission biases (2014a) and his "M.O.P.E.D.S." model for understanding complex linguistic causation (2014b). Such grounding might also open modeling proposals up to more productive critical scrutiny. Both treatments would do well to pay closer critical and empirical attention to recent discussions in linguistic semiotics having to do with diagrams and the nature of diagrammatization (see Shapiro 2002; Nöth 2008; Pelkey 2013a, 2015). Such insights may be of use to the Rhetoric Culture project as well, due to the close relationship they share with domain general processes and structures of analogy. As Strecker and Tyler acknowledge, analogy is "the most evident form in which rhetoric manifests itself in culture" (2009:4).

Regarding other movements within anthropology that the Rhetoric Culture project might turn to for better grounding, research in chiasmus patterning would almost certainly benefit from dialogue with Dorothy K. Washburn and Donald W. Crowe's cultural symmetry theory, given that the chiasmus pattern is also an (a)symmetry-oriented phenomenon. Cultural symmetry theory bridges socio-cultural and archaeological branches of anthropology, blending insights from mathematical group theory to identify, track, and study both the significance and development of geometric patterns in material culture. Washburn (2004) and Washburn and Crowe (2004) move beyond their founding vision (published in Washburn and Crowe 1998) to integrate perspectives from ethnography, biological and physical anthropology, developmental psychology, and semiotic anthropology. In this connection, more careful attention to discussions of chiasmus patterning as a pattern of marked symmetry (i.e., "antisymmetry") instead of a form of mere symmetry would serve the movement well. Examples of conflation between chiasmus and mere symmetry in Wiseman and Paul (2014) are implied in numerous passages (see e.g., Hariman 2014:52, 62; Thomas-Fogiel 2014:92; Vanier 2014:143). Even Paul's (2014) prescient discussions of chiasmus typologies might benefit from more adequate grounding in general theories of symmetry and markedness. Further transdisciplinary discussions of the symmetry-antisymmetry contrast featuring linguistic patterning can be found in Nöth $(1994,1998)$ and Pelkey (2013b). 
Finally, insights from phenomenologically embodied cognition may be of use to both the Rhetoric Culture Project and to Enfield et al.'s new vision for linguistic anthropology. Phenomenologically embodied cognition builds on early work in the area (e.g., Lakoff and Johnson 1987; Varela et al. 1991) to draw attention to the importance of kinesthetic movement and corporeal feeling in human cognition (e.g., Johnson 2007; Sheets-Johnstone 2011). If we wish to develop the "idea of a fundamental rhetoric" (Oesterreich 2009:57), or more specifically, if we actually wish to attempt explaining why and how it is that "chiasmus provides a powerful explanatory principle" (Paul and Wiseman 2014:4), it will be necessary to inquire into the origins of figures, tropes, and images beyond vague references to human desire, or the human poetic impulse, or the observation of cultural dichotomies.

Fernandez's (2009) look at foundational tropes in philosophy from the pre-Socratics to the present, for instance, notes that root tropes tend to be polarized: analytic-synthetic, northern-southern, container-content (2009: 170). These he takes to be rhetorical foundations but argues in passing that the various dichotomies that emerge between these root tropes may be more deeply rooted in the gender trope across cultures. While this is a fair bid for grounding, it is ultimately a mere deferral of the question, since we must also ask after the origins of the gender trope. Eventually, such questioning must turn (or return) to bodily features, structures, and experiences. This is especially important for anything approaching truth claims since such phenomena themselves emerge from natural processes that are congruent, or continuous, with processes and products of evolution that are found in other animal species and even biological phenomena more distant.

Within the Rhetoric Culture Project, Paul $(2009,2014)$ pushes hardest in this direction, asking whether or not art and rhetoric can not only help us "fit chaotic experience into orderly forms and patterns, but also to find such patterns and forms within experience" (2009:114). This does not yet appear to be a concern of the project as a whole, however; and one practitioner even asserts (with little recognizable argumentation) that the figure is in no way related to the natural world (Hariman 2014:46-47). Insights from French phenomenologist Maurice Merleau-Ponty have at least induced doubts over Hariman's assertion for those involved in discussions of chiasmus (see Paul and Wiseman 2014; Paul 2014; Vanier 2014; Thomas-Fogiel 2014). Merleau-Ponty finished his career with a provocative discussion of the significance of various chiastic features that mark basic human experience, such as seeing while being seen or hearing oneself speak (1960).

As Thomas-Fogiel (2014) argues, this is not an arbitrary relation but "an identity within opposition, a crossing that institutes the very elements it puts in relation," ultimately implementing "a new logic: that of the sensible" (2014:111-112). Remarkably, Hariman himself picks up on a similar theme later in his own essay, suggesting from a sociocultural perspective that it 
would seem reasonable to find some aspect of chiastic structure in our own bodily experience. He considers both the spread-eagle $\mathrm{X}$ posture and the experience of criss-crossing vision, settling on the latter as a plausible explanation (2014:62). As I show in Pelkey (2013c) there is no need to choose between the two. The larger point to be made here, though, is related to grounding: If, following Hariman's apparent line of reasoning, we insist that the patterned, (a)symmetrical organization of human bodily structures which inform the chiasmus figure are not themselves in relationships of continuity with patterned (a)symmetries found elsewhere in the natural world, we are faced with a grounding crisis of anti-evolutionary proportions, a crisis of our own making.

\section{Critical problems}

As mentioned above, in announcing their new vision for linguistic anthropology, the editors of the Enfield et al. collection employ a "broad-view vs. narrow-view" trope to distinguish themselves from their "well-institutionalized" colleagues in the American Anthropological tradition. Is such a strategy necessary or warranted? What purpose does it serve? As discussed above, the (virtual alter ego) tradition in question also shows many signs of opening up to trans-disciplinary conversations and semiotic technologies such as those being promoted by the volume editors; furthermore, many who would otherwise affiliate with this tradition are themselves prominent contributors to the handbook. The broad-versus-narrow trope seems to presume, at best, an image-schematic metaphor of conceptual containment such that SELF IS CONTAINER, OTHER IS CONTAINED. This, in turn, easily devolves into an imperialist move (conquest and enlightenment of the narrow-minded) and may just as easily be perceived as a dismissive gesture (by those whose identities are being represented by straw men). Nor is the use of this problematic trope limited to the volume introduction.

The same trope is employed by Bernard Bate (2014) later in the volume to frame "two views of rhetoric: a broad one consisting of phenomenologies of specific language use and a narrow one that is basically Western rhetoric" (2014:537). Included in this camp, according to Bate (2014:542), are Strecker and Tyler (2009), and by proxy, presumably, the entire Rhetoric Culture Project. Unfortunately, no further attention or discussion are devoted to the rich and nuanced inquiry being carried out by practitioners in the Rhetoric Culture Project, neither in Bates' chapter nor elsewhere in the handbook. This rather cursory dismissal is premised on the project's generally positive orientation to Kenneth Burke's theories of rhetoric (e.g., 1969), which are prone to lead rhetoricians to privilege the status of persuasion and "neglect the socio-semiotic variation of self and personhood indexed in discursive interaction" (Bate 2014:543). 
Interestingly, the larger critical problem underlying such rhetorical broadview-narrow-view pronouncements is identified and discussed at length later in the handbook by one of the volume editors, Paul Kockelman. Kockelman offers "a critique of mediation as critique" (2014:617), a critical perspective on an activity he dubs "meta-mediationism," arguing that linguistic anthropologists have devoted entirely too much attention to the mere critique of narrow strategies of mediation. Imagine, for example one colleague castigating another colleague for bracketing off too many additional mediating influences in her production of a descriptive grammar or in her careful transcription of a conversation. Since "[e]verything mediates everything else at some degree of remove," such critical approaches are themselves immune from attack, allowing us "to almost effortlessly generate an infinite number of critiques" (2014:618). According to Kockelman, the basic argument behind such shallow critiques can be summed up colloquially thus: "You are not wide enough in your vision" (2014:618).

Whether or not linguistic anthropologists, generally considered, are currently wide enough in their vision, I wish to suggest that the Rhetoric Culture Project (RCP) is, on the whole, much wider in its vision than Bate gives the movement credit for in his implicit summary dismissal (2014:543). First, even in the movement's inaugural collection, Strecker and Tyler claim that the vision behind their approach is "based on a wide concept of rhetoric" (2009:ix). They go on to elaborate that their approach eschews the idea of a unified "theory of rhetoric" (Tyler and Strecker 2009:22). Rather, there are "ethnographic accounts of rhetorical practices" that might be characterized as "rhetoric in culture" and "critical accounts of those rhetorical practices" that are closer to "the rhetoric of culture," both of which tend to proceed hand-in-hand (Tyler and Strecker 2009:22-23).

Although contributors such as Meyer (2009) situate the project in the stream of classical rhetoric from the Sophists to Vico to Schopenhauer to Burke, Meyer also takes prominent detours into the work of early ethnographers like Lafitau (1681-1746) and Leenhardt (1878-1954). To Bate's credit, many RCP practitioners rally around the Western rhetorical concept of persuasion (see Maranda 2009:208; Hariman 2009:223; Salazar 2009:153154; Herzfeld 2009:201), but often in ways that might qualify equally well as the study of communication pragmatics more generally-as we find elaborated in Oesterreich (2009:49), who recommends the study of "prophesizing, narrating, proclaiming, questioning, explicating, contradicting ... pleading, requesting, advising, impelling, prescribing, ordering, seducing ... delighting, amusing, diverting, praising, paying tribute, glorifying, and so on."

Bate's own wider point is that all rhetorics cross-culturally must be recognized as "ethnorhetorics" (2014:553), lest would-be rhetorical anthropologists "elevate their own unrecognized ethnocategories to the status of universal law” (2014:544). Empirical-ethnographic applications supporting Bate's 
agenda can be found alive and well in the RCP movement in works such as Strecker (2011), Bollig (2014), and Lewis (2014). In addition to contributions already cited above, theory-critical affirmation of Bates' agenda can be found in Rumsey (2009; see also Wiseman 2009:86 for further self-critical attention), who is intent on challenging classical European notions of rhetoric rooted in highly questionable language ideologies involving "the dualism of words and things; talk versus action; real world events versus ways of talking about them" (citing Rumsey 1990:352), that are rejected as inadequate for cross-cultural research and understanding (2009:130). However, just as tropes were once assumed to be restricted to the humanities and are now acknowledged to also operate in the physical sciences, tropes are also operative in social and linguistic systems "in parts of the world where that distinction has played no such role" (2009:141). The discovery and clarification of cross-cultural patterns also found to function as dynamic models is a key contribution of the Rhetoric Culture Project, the chiasmus pattern in particular.

\section{Symbiotic modeling in linguistic anthropology}

Examples of chiastic modeling in the Enfield et al. (2014) handbook are manifold, even in terms of surface tokens. In terms of underlying thematic types, the figure is arguably ubiquitous. The text itself opens with a richly complex chiasmus related to the unity and diversity of human language (2014:1); and many of the most cogent arguments in the collection rely heavily on chiastic cognition to make their cases. Here I briefly illustrate these claims by summarizing representative types and tokens and offering a verbatim sampling for evidence. This gesture is both critical-reflexive and dataempirical, showing examples of chiasmus patterning ranging from overt chiastic surface forms and overt chiastic metaphors to discussions of reversals, oppositional relations, and more complex intertwining relations employed in the collection.

The most readily identifiable of these strategies are overt chiastic surface forms, including simple, complex, and ellipsis constructions. Simple surface examples include Enfield's citation of Zipf's "economy of tools-for-jobs and jobs-for-tools" (Enfield 2014a:70); Kockelman's observation of "humanhuman interaction when mediated by machines" contrasted with "machinemachine interaction when mediated by humans" (2014b:725); Gershon and Manning's observation that "when texts enter into new contexts, they both are transformed and transform the contexts" (2014:562). Uses of "and vice versa" constructions across the text also qualify as overt instances of chiasmus, via ellipsis. Consider Levinson's observation that "language is a kind of bio-cultural hybrid, with the culture part evolved to exploit the biological part, and vice versa" (2014:320). See Gershon and Manning (2014:572), Blench (2014:675), and Kockelman (2014b:721) for further examples. Less overt 
chiastic ellipses can also be noted, such as Stasch's observation (2014:633) that, "The form or act is defined and supported by concepts, understandings, and other forms or acts in other layers of life, and it defines and supports them in turn." It is no mistake that Stasch goes on to explicitly describe this relation as "semiotic" (2014:633).

Slightly more complex surface chiasmi also appear, often relying on parallels between semantic domains as much as polysemy and derived forms to frame their arguments. Dixon's chiasmus between anthropology and linguistics cited in the introduction above (and in his own introduction, 2014:29), for instance, is further elaborated in his own chapter's conclusion: "A linguist must do a fair amount of anthropological work in order to explain features of the language. Likewise, and contrariwise, an anthropologist will miss a good deal if they do not acquire a good knowledge of the grammar" (2014:35). Similarly, referencing linguistic anthropology's overlapping commitments with socio-cultural anthropology, Stasch states that "many linguistic anthropologists give serious weight to the study of extralinguistic levels of people's lives, and... most sociocultural anthropologists take aspects of language as major parts of their subject" (2014:632).

Implicit chiastic relations are especially profuse in the volume. Consider Faudree and Hansen's observation on "how tightly [language] is bound to culture through shared history, the two having 'grown up together, constantly influencing each other"' (2014:227, citing Whorf 1956:156). Similarly, we find Levinson's observation regarding genetic distribution and elaboration of sign language populations: "Both the biology and the culture depend on one another" (2014:320). Sidnell's summary description of his "architecture of intersubjectivity" is framed such that "previous, current, and next components of a sequential organization interlock and reinforce one another" (2014:364). Stasch discusses "interconnections between linguistic and morethan-linguistic layers of human worlds" (2014:627). For further examples, see Sidnell (2014:369) on reciprocity of perspective, Dediu (2014:698) on "inter-related levels" of interaction between biology and language, and Gershon and Manning (2014:572-573) on establishing "symmetry between human and non-human mediation".

At the thematic and topical level, the Cambridge handbook includes many discussions of reflexivity, along with compact statements of reflexive relations, both of which also rely on cognitive chiasmus (Pelkey 2013b, 2013c), or "implicit" chiastic modeling. Enfield et al.'s remark that language is both a tool and an object of accountability (2014:13) falls under this category, as do Brandom's reflections on what is happening when we "talk or think about what we are talking or thinking about" (2014:362, emphasis in the original). Goldin-Meadow's remarks on the inseparability of speech and gesture (2014:79) have connections here as well. Elsewhere, Tavárez argues that ritual speech involves "world-changing reflexive semiosis" (2014:530). There are 
discussions of "token reflexivity" (Rumsey 2014:405, 416), "refracted reflexivity" (Kockelman 2014b:722), reflexivity in new technology (Gershon and Manning 2014:567), "reflexivity and indeterminacy" (Tavárez 2014:528529), "self-reflexive claims" (Kockelman 2014a:617), and the "self-reflexivity of human affairs" (Enfield 2014b:335). Furthermore, Kockelman wishes to "understand and critique linguistic anthropology's approach to understanding and critique" (2014a:608); and in a later contribution he argues that "computers are essentially text-generated and text-generating devices" (2014b:711).

The volume also features discussions of chiastic reversals, such as a perspectival flip-flop on the relationship between mind and language (Enfield et al. 2014:11) and historical oscillations between linguistic diversity versus language universals (Bickel 2014:102), also discussed in Dediu (2014:686). Troves of data on topics of related interest could continue to be detailed, such as the never-ending discussions of oppositional pairs and notable discussions of diagrammatic iconicity, or relations between relations. Perhaps most "fitting" of all, from an enactive cognitive perspective, we should note the presence of bodily chiastic metaphors that pepper the text, such as "on one hand ... on the other hand" constructions (see Levinson 2014:310-311, Stasch 2014:627-628) and "hand-in-hand" relations (see e.g., Kockelman 2014:726, Levinson 2014:310).

In all such cases, just as Enfield (2014a:71) notes of his item-system relations, "Neither ... can exist without the other, and the challenge is to characterize the relation between the two-this relation being the one thing that defines them both." In fact, linguistic anthropology's newfound openness seems to be rooted in this growing discovery: that is, that it makes less and less sense to isolate previously opposed, contrary, or apparently contradictory perspectives from each other. Dediu finds this to be true in his inquiry as well, noting that "genetic and environmental factors are fundamentally in interaction and it does not make much sense to even consider them in isolation" (Dediu 2014:693, emphasis in the original). Kockelman (2014:715) makes a similar observation in his own field of inquiry, modeling the issue with an overt double chiasmus or chiastic helix: "a stringless device is like an organism without its environment; just as a deviceless string is like an environment without an organism. Neither makes much sense except in relation to the other."

\section{The promise of chiasmus}

Symbiotically relating to each other is what organisms and environments do. The uniquely human quest involves an ongoing effort to make sense of relations that are symbiotic. As a fundamental mode of human modeling, chiasmus' latent promise is largely stored in the leverage it affords for grappling with (and feasting on) what Roger Lohmann has dubbed "delicious dueling 
dualisms" (2010:1). Andrew White (2015, drawing on Mosko 2005) affirms what anthropologists continue to discover and rediscover around the world: that is, the "apparent universality of contradictory, dualistic, and/or oppositional symbolic structures embedded in human cultures" (2015:146). As Lohmann goes on to claim, "problematic as they are, binary pairs are congenial to human thought" (2010:1).

But are they? Perhaps Lohmann, along with the rest of us, could be missing something important. Polarized dichotomies are certainly congenital in human thought, but are they also congenial to it? As the Rhetoric Culture Project shows, it may much rather be the case that the problematization and reconciliation of anti-thetical binary pairs is what proves truly to be congenial to human thought. The conditioned acceptance or subconscious assumption of polar oppositions, on the other hand, is often less than helpful, whether we are attempting to ward off harmful escalations, understand new material, learn new skills, forge fresh dialogues, identify hidden power structures, or make new discoveries. Consider, for instance, the various entrenched binaries inherited, in many Western cultures, from Cartesian dualism: nature-culture, subject-object, body-mind, animal-human, thinking-feeling (see Merleau-Ponty 1966; Johnson 2007; Russell 2010:5). Unless we are able to construct and identify deliberate models that call them into question or bring them into dialogue, such polarized dogmas will continue to hamper and hamstring our understanding of the nature of human being, in anthropological theory and practice.

Of the many dichotomies that may be identified in contemporary anthropology as a social movement, one emerges as a "profound divide" (Harkin 2010:34), separating "postmodern" Boasian relativists on one hand from "science"-oriented, data-collecting empiricists on the other (2010: 28ff.). From Andrew A. White's perspective, "Tensions between the study of the particular and the study of the general, between the emphasis on history and the discovery of process, between anthropology as a scientific humanity and anthropology as a humanistic science, remain unresolved today" (2015:143). To feel as if one must decide between anthropology as humanity versus anthropology as science, to assume that one must engage either in cultural criticism or cultural fieldwork, is part of the problem, since both approaches are needed; the other half of the problem emerges from suggestions that there might be no distinction between the two. This is the problem of mere holism (see Harkin 2010:37). Taking clues from Lévi-Strauss' (1966) paradox of suppressed differences, Harkin (2010) finds that in some way such divides need to be both called into question on one hand but affirmed and protected on the other. Much as Enfield claims for his proposed basic level set of causal frames mentioned above, the categories need to be approached as "conceptually distinct but interconnected" (2014b:329). 
This, in fact, is a key function of chiasmus: to keep apart while bringing together. Properly considered, however, this is not the end of chiasmus. The leverage chiasmus provides also enables us to transcend oppositions by bringing a third (or further) blended possibility into view-new modes of mutual interdependence through which the oppositions themselves become more authentic, more enriched, more full of possibility. This is illustrated nicely in the story of a simple diagrammatic hypothesis mentioned above, first shared quietly between two colleagues, who mused that "just as rhetoric is founded in culture, culture is founded in rhetoric" (Tyler and Strecker's 2009:4) - a musement that went on to birth a movement of its own. Insights from this movement, in turn, lead me to propose here that in some sense a similar pattern might hold between rhetoric culture theory's master figure and the semiotic openness of contemporary linguistic anthropology.

\section{Acknowledgments}

This research was supported by the Social Sciences and Humanities Research Council of Canada: SSHRC-IDG \#430-2015-01226 “Steps to a Grammar of Embodied Symmetry."

\section{References cited}

Bate, Bernard

2014 Oratory, Rhetoric, Politics. In The Cambridge Handbook of Linguistic Anthropology. N. J. Enfield, Paul Kockelman, and Jack Sidnell, eds. Pp. 537-558. Cambridge: Cambridge University Press.

Bateson, Gregory, John D. Jackson, Jay Haley, and John H. Weakland 1956 Toward a Theory of Schizophrenia. Behavioural Science 1(4): 251-254.

Bickel, Balthasar

2014 Linguistic Diversity and Universals. In The Cambridge Handbook of Linguistic Anthropology. N. J. Enfield, Paul Kockelman, and Jack Sidnell, eds. Pp. 102-127. Cambridge: Cambridge University Press.

Blench, Robert M.

2014 Language and Archaeology: State of the Art. In The Cambridge Handbook of Linguistic Anthropology. N. J. Enfield, Paul Kockelman, and Jack Sidnell, eds. Pp. 661-685. Cambridge: Cambridge University Press.

Bloch, Maurice

2012 Anthropology and the Cognitive Challenge. New Departures in Anthropology. Cambridge: Cambridge University Press.

Bollig, Ben

2014 Travestis, Michês and Chiasmus: Crossing and Cross-Dressing in the Work of Néstor Perlongher. In Chiasmus and Culture. Studies in Rhetoric and Culture, 6. Boris Wiseman, and Anthony Paul, eds. Pp. 161-185. Oxford: Berghahn Books.

Brandom, Robert B.

2014 Intentionality and Language. In The Cambridge Handbook of Linguistic Anthropology. N. J. Enfield, Paul Kockelman, and Jack Sidnell, eds. Pp. 347-363. Cambridge: Cambridge University Press. 
Brown, Penelope, and Suzanne Gaskins

2014 Language Acquisition and Language Socialization. In The Cambridge Handbook of Linguistic Anthropology. N. J. Enfield, Paul Kockelman, and Jack Sidnell, eds. Pp. 187-226. Cambridge: Cambridge University Press.

Burke, Kenneth

1969[1950] A Rhetoric of Motives. Berkeley: University of California Press.

Cannada Bartoli Vincenzo

2009 Practice of Rhetoric, Rhetoric of Practice. In Culture and Rhetoric. Studies in

Rhetoric and Culture, 1. Ivo Strecker, and Stephen Tyler, eds. Pp. 74-84. Oxford:

Berghahn Books.

Carrithers, Michael

2009 Culture, Rhetoric and the Vicissitudes of Life. Studies in Rhetoric and Culture, 2.

Oxford: Berghahn Books.

Dediu, Dan

2014 Language and Biology: The Multiple Interactions between Genetics and Language. In The Cambridge Handbook of Linguistic Anthropology. N. J. Enfield, Paul Kockelman, and Jack Sidnell, eds. Pp. 686-708. Cambridge: Cambridge University Press.

Deely, John

2001 Four Ages of Understanding: The First Postmodern Survey of Philosophy from Ancient Times to the Turn of the Twenty-first Century. Toronto: University of Toronto Press.

2012 Analytic Philosophy and the Doctrine of Signs. American Journal of Semiotics 28(3/4):325-363.

Dingemanse, Mark, and Simeon Floyd

2014 Conversation across Cultures. In The Cambridge Handbook of Linguistic Anthropology. N. J. Enfield, Paul Kockelman, and Jack Sidnell, eds. Pp. 447-480. Cambridge: Cambridge University Press.

Dixon, R. M. W.

2014 Basics of a Language. In The Cambridge Handbook of Linguistic Anthropology. N. J. Enfield, Paul Kockelman, and Jack Sidnell, eds. Pp. 29-47. Cambridge: Cambridge University Press.

Eckert, Penelope

2014 Sociolinguistics: Making Quantification Meaningful. In The Cambridge Handbook of Linguistic Anthropology. N. J. Enfield, Paul Kockelman, and Jack Sidnell, eds. Pp. 626-643. Cambridge: Cambridge University Press.

Enfield, N. J.

2014a The Item/System Problem. In The Cambridge Handbook of Linguistic Anthropology. N. J. Enfield, Paul Kockelman, and Jack Sidnell, eds. Pp. 48-77. Cambridge: Cambridge University Press.

2014b Causal Dynamics of Language. In The Cambridge Handbook of Linguistic Anthropology. N. J. Enfield, Paul Kockelman, and Jack Sidnell, eds. Pp. 325-342. Cambridge: Cambridge University Press.

Enfield, N. J., Paul Kockelman, and Jack Sidnell

2014a Introduction: Directions in the Anthropology of Language. In The Cambridge Handbook of Linguistic Anthropology. N. J. Enfield, Paul Kockelman, and Jack Sidnell, eds. Pp. 1-24. Cambridge: Cambridge University Press.

Enfield, N. J., Paul Kockelman, and Jack Sidnell, eds.

2014 The Cambridge Handbook of Linguistic Anthropology. Cambridge: Cambridge University Press. 
Fauconnier, Gilles, and Mark Turner

2002 The Way We Think: Conceptual Blending and the Mind's Hidden Complexities.

New York: Basic Books.

Faudree, Paja, and Magnus Pharao Hansen

2014 Language, Society and History: Toward a Unified Approach? In The Cambridge Handbook of Linguistic Anthropology. N. J. Enfield, Paul Kockelman, and Jack Sidnell, eds. Pp. 227-249. Cambridge: Cambridge University Press.

Fernandez, James W.

2009 Tropical Foundations and Foundational Tropes of Culture. In Culture and Rhetoric.

Ivo Strecker and Stephen Tyler, eds. Pp. 166-181. Studies in Rhetoric and Culture, 1.

Oxford: Berghahn Books.

Fleming, Luke, and Michael Lempert

2014 Poetics and Performativity. In The Cambridge Handbook of Linguistic Anthropology. N. J. Enfield, Paul Kockelman, and Jack Sidnell, eds. Pp. 485-515. Cambridge: Cambridge University Press.

Gershon, Ilana, and Paul Manning

2014 Language and Media. In The Cambridge Handbook of Linguistic Anthropology. N. J. Enfield, Paul Kockelman, and Jack Sidnell, eds. Pp. 559-576. Cambridge: Cambridge University Press.

Goldin-Meadow, Susan

2014 Language and the Manual Modality: The Communicative Resilience of the Human Species. In The Cambridge Handbook of Linguistic Anthropology. N. J. Enfield, Paul Kockelman, and Jack Sidnell, eds. Pp. 78-101. Cambridge: Cambridge University Press. Graber, Kathryn E.

2015 On the Disassembly Line: Linguistic Anthropology in 2014. American Anthropologist 117(2):350-363.

Gudeman, Stephen

2009 Economic Persuasions. Studies in Rhetoric and Culture, 3. Oxford: Berghahn Books.

Hariman, Robert

2009 Future Imperfect: Imagining Rhetorical Cultural Theory. In Culture And Rhetoric. Ivo Strecker and Stephen Tyler, eds. Pp. 221-237. Studies in Rhetoric and Culture, 1. Oxford: Berghahn Books.

2014 What Is a Chiasmus? Or, Why the Abyss Stares Back. In Chiasmus and Culture. Boris Wiseman, and Anthony Paul, eds. Pp. 45-68. Studies in Rhetoric and Culture, 6. Oxford: Berghahn Books.

Hariman, Robert, and Ralph Cintron

2015 Culture, Catastrophe and Rhetoric. Studies in Rhetoric and Culture, 7. Oxford: Berghahn Books.

Harkin, Michael E.

2010 Uncommon Ground: Holism and the Future of Anthropology. Reviews in Anthropology 39(1):25-45.

Herzfeld, Michael

2009 Convictions: Embodied Rhetorics of Earnest Belief. In Culture And Rhetoric. Ivo Strecker, and Stephen Tyler, eds. Pp. 182-206. Studies in Rhetoric and Culture, 1. Oxford: Berghahn Books.

Kockelman, Paul

2014a Linguistic Anthropology in the Age of Language Automata. In The Cambridge Handbook of Linguistic Anthropology. N. J. Enfield, Paul Kockelman, and Jack Sidnell, eds. Pp. 708-733. Cambridge: Cambridge University Press. 
2014b Linguistic Anthropology and Critical Theory. In The Cambridge Handbook of

Linguistic Anthropology. N. J. Enfield, Paul Kockelman, and Jack Sidnell, eds.

Pp. 603-625. Cambridge: Cambridge University Press.

Lakoff, George, and Mark Johnson

1980 Metaphors We Live By. Chicago: University of Chicago Press.

Levinson, Stephen C.

2014 Language Evolution. In The Cambridge Handbook of Linguistic Anthropology. N. J.

Enfield, Paul Kockelman, and Jack Sidnell, eds. Pp. 309-325. Cambridge: Cambridge

University Press.

Lévi-Strauss, Claude

1955 Tristes Tropiques. Paris: Plon.

1958 Anthropologie structurale. Paris: Plon.

1966 The Savage Mind. Chicago: University of Chicago Press.

1978 The Origin of Table Manners. New York: Harper \& Rowe.

1994 The Raw and the Cooked. London: Pimlico.

1995 The Story of Lynx. Chicago: University of Chicago Press.

Lewis, E. Douglas

2014 Parallelism and Chiasmus in Ritual Oration and Ostension in Tana Wai Brama,

Eastern Indonesia. In Chiasmus and Culture. Boris Wiseman, and Anthony Paul, eds.

Studies in Rhetoric and Culture, 6. Pp. 187-218. Oxford: Berghahn Books.

Lissner, Patricia Anne

2007 Chi-Thinking: Chiasmus and Cognition. Ph.D. dissertation, University of Maryland.

Lohmann, Roger Ivar

2010 Editorial Introduction: Delicious Dueling Dualisms. Reviews in Anthropology 39(1):1-2.

Maranda, Pierre

2009 An Epistemological Query. In Culture and Rhetoric. Ivo Strecker and Stephen Tyler, eds. Pp. 207-210. Studies in Rhetoric and Culture, 1. Oxford: Berghahn Books.

Merleau-Ponty, Maurice

1960 The Intertwining - the Chiasm. In Le Visible et L'invisible: The Visible and the Invisible. Claude Lefort, ed. Alphonso Lingis, tran. Pp. 130-155. Editions Gallimard, Paris, 1964. Evanston: Northwestern University Press.

Meyer, Christian

2009 Precursors of Rhetoric Culture Theory. In Culture and Rhetoric. Ivo Strecker and

Stephen Tyler, eds. Pp. 31-48. Studies in Rhetoric and Culture, 1. Oxford: Berghahn Books.

Meyer, Christian, and Felix Girke

2011 The Rhetorical Emergence of Culture. Studies in Rhetoric and Culture, 4. Oxford: Berghahn Books.

Mosko, Mark S.

2005 Peace, War, Sex and Sorcery: Nonlinear Analogical Transformation in the Early Escalation of North Mekeo Sorcery and Chiefly Practice. In On The Order Of Chaos: Social Anthropology and the Science of Chaos. Mark S. Mosko, and Frederick H. Damon, eds. Pp. 166-205. New York: Berghahn Books.

Nöth, Winfried

1994 Opposition at the Root of Semiosis. In Origins of Semiosis: Sign Evolution in Nature and Culture. Winfried Nöth ed. Pp. 37-60. Berlin: Mouton de Gruyter.

1998 Symmetry in Signs and in Semiotic Systems. Interdisciplinary Journal for Germanic Linguistics and Semiotic Analysis 3(1):47-62. 
2008 Semiotic Foundations of Natural Linguistics and Diagrammatic Iconicity. In Naturalness and Iconicity in Language. Klaas Willems, and Ludovic De Cuypere, eds. Pp. 73-100. Iconicity in Language and Literature, 7. Amsterdam: John Benjamins.

Oesterreich, Peter L.

2009 Homo Rhetoricus. In Culture and Rhetoric. Ivo Strecker and Stephen Tyler, eds. Pp. 49-58. Studies in Rhetoric and Culture, 1. Oxford: Berghahn Books.

Paul, Anthony

1992 The Torture of the Mind: Macbeth, Tragedy and Chiasmus. Amsterdam: Academisch Proefschrift.

2009 When Fair Is Foul and Foul Is Fair: Lessons from Macbeth. In Culture And Rhetoric. Ivo Strecker and Stephen Tyler, eds. Pp. 104-114. Studies in Rhetoric and Culture, 1. Oxford: Berghahn Books.

2014 From Stasis to Ékstasis: Four Types of Chiasmus. In Chiasmus and Culture. Boris Wiseman and Anthony Paul, eds. Pp. 19-44. Studies in Rhetoric and Culture, 6. Oxford: Berghahn Books.

Peirce, Charles Sanders

1904 [1998] New Elements (Kaina Stoicheia). In The Essential Peirce: Selected Philosophical Writings. Vol. 2 (1893-1913). Peirce Edition Project eds. Pp. 300-324. Bloomington: Indiana University Press.

Pelkey, Jamin

2011 Dialectology as Dialectic: Interpreting Phula Variation, Trends in Linguistics: Studies and Monographs, 229. Berlin: De Gruyter Mouton.

2013a Analogy, Automation and Diagrammatic Causation: The Evolution of TibetoBurman *lak. Studies in Language 37(1):144-195.

$2013 \mathrm{~b}$ Chiastic Antisymmetry in Language Evolution. The American Journal of Semiotics 29(1-4):39-68.

2013c Cognitive Chiasmus: Embodied Phenomenology in Dylan Thomas. Journal of Literary Semantics 42(1):79-114.

2015 Deep Congruence between Linguistic and Biotic Growth: Evidence for Semiotic Foundations. In Biosemiotic Perspectives on Language and Linguistics. Ekaterina Velmezova, Stephen J. Cowley and Kalevi Kull, eds. Pp. 97-119. Biosemiotics, 13. Berlin: Springer.

Reyes, Angela

2014 Linguistic Anthropology in 2013: Super-New-Big. American Anthropologist 116(2):366-378.

Rice, Keren

2014 Endangered Languages. In The Cambridge Handbook of Linguistic Anthropology. N. J. Enfield, Paul Kockelman, and Jack Sidnell, eds. Pp. 285-308. Cambridge: Cambridge University Press.

Rumsey, Alan

2009 Rhetoric, Truth and the Work of Trope. In Culture and Rhetoric. Ivo Strecker and Stephen Tyler, eds. Pp. 117-149. Studies in Rhetoric and Culture, 1. Oxford: Berghahn Books.

2014 Language and Human Sociality. In The Cambridge Handbook of Linguistic Anthropology. N. J. Enfield, Paul Kockelman, and Jack Sidnell, eds. Pp. 400-421. Cambridge: Cambridge University Press.

Russell, Nerissa

2010 Navigating the Human-Animal Boundary. Reviews in Anthropology 39(1):3-24. 
Salazar, Philippe-Joseph

2009 Figuration, a Common Ground of Rhetoric and Anthropology. In Culture and Rhetoric. Ivo Strecker and Stephen Tyler, eds. Pp. 150-167. Studies in Rhetoric and Culture, 1. Oxford: Berghahn Books.

2014 Forking: Rhetoric $\chi$ Rhetoric. In Chiasmus and Culture. Boris Wiseman, and Anthony Paul, eds. Pp. 124-141. Studies in Rhetoric and Culture, 6. Oxford: Berghahn Books.

Sandler, Wendy, Mark Aaronoff, Carol Padden, and Irit Meir

2014 Language Emergence: Al-Sayyid Bedouin Sign Language. In The Cambridge Handbook of Linguistic Anthropology. N. J. Enfield, Paul Kockelman, and Jack Sidnell, eds. Pp. 250-284. Cambridge: Cambridge University Press.

Shapiro, Michael

2002 Aspects of a Neo-Peircean Linguistics: Language History as Linguistic Theory. In The

Peirce Seminar Papers: Essays in Semiotic Analysis. Pp. 108-125. Oxford: Berghahn.

Shaw, Marvin

1988 The Paradox of Intention: Reaching the Goal by Giving Up the Attempt to Reach It. Atlanta: Scholars Press.

Sheets-Johnstone, Maxine

2011 The Primacy of Movement. 2nd edition. Advances in Consciousness Research, 82. Amsterdam: John Benjamins.

Sidnell, Jack

2014 The Architecture of Intersubjectivity Revisited. In The Cambridge Handbook of Linguistic Anthropology. N. J. Enfield, Paul Kockelman, and Jack Sidnell, eds. Pp. 364-399. Cambridge: Cambridge University Press.

Sidnell, Jack, and N. J. Enfield

2014 The Ontology of Action, in Interaction. In The Cambridge Handbook of Linguistic Anthropology. N. J. Enfield, Paul Kockelman, and Jack Sidnell, eds. Pp. 423-446. Cambridge: Cambridge University Press.

Silverstein, Michael

2014 Denotation and the Pragmatics of Language. In The Cambridge Handbook of Linguistic Anthropology. N. J. Enfield, Paul Kockelman, and Jack Sidnell, eds. Pp. 128-157. Cambridge: Cambridge University Press.

Stasch, Rupert

2014 Linguistic Anthropology and Sociocultural Anthropology. In The Cambridge Handbook of Linguistic Anthropology. N. J. Enfield, Paul Kockelman, and Jack Sidnell, eds. Pp. 626-643. Cambridge: Cambridge University Press.

Strecker, Ivo

2011 Ethnographic Chiasmus: Essays on Culture, Conflict, and Rhetoric. East Lansing: Michigan State University Press.

2014 Chiasmus and Metaphor. In Chiasmus and Culture. Boris Wiseman and Anthony Paul, eds. Studies in Rhetoric and Culture, 6. Pp. 69-88. Oxford: Berghahn Books.

Strecker, Ivo, and Stephen Tyler

2009 Introduction. In Culture and Rhetoric. Ivo Strecker and Stephen Tyler, eds. Studies in Rhetoric and Culture, 1. Pp. 1-18. Oxford: Berghahn Books.

Strecker, Ivo, and Stephen Tyler, eds.

2009 Culture and Rhetoric. Studies in Rhetoric and Culture, 1. Oxford: Berghahn Books.

Strecker, Ivo, and Markus Verne, eds.

2013 Astonishment and Evocation: The Spell of Culture in Art and Anthropology. Studies in Rhetoric and Culture, 5. Oxford: Berghahn Books. 
Tavárez, David

2014 Ritual Language. In The Cambridge Handbook of Linguistic Anthropology. N. J. Enfield,

Paul Kockelman, and Jack Sidnell, eds. Pp. 516-536. Cambridge: Cambridge University Press.

Thomas-Fogiel, Isabelle

2014 Chiasm in Merleau-Ponty: Metaphor or Concept?. In Chiasmus and Culture. Boris Wiseman and Anthony Paul, eds. Pp. 91-115. Studies in Rhetoric and Culture, 6. Oxford: Berghahn Books.

Thompson, Sandra A., and Elizabeth Couper-Kuhlen

2014 Language Function. In The Cambridge Handbook of Linguistic Anthropology. N. J.

Enfield, Paul Kockelman, and Jack Sidnell, eds. Pp. 158-182. Cambridge: Cambridge

University Press.

Tyler, Stephen

2014 Chiasmi Figuring Difference. In Chiasmus and Culture. Boris Wiseman and Anthony Paul, eds. Pp. 116-123. Studies in Rhetoric and Culture, 6. Oxford: Berghahn Books.

Tyler, Stephen, and Ivo Strecker

2009 The Rhetoric Culture Project. In Culture and Rhetoric. Ivo Strecker and Stephen Tyler, eds. Pp. 1-18. Studies in Rhetoric and Culture, 1. Oxford: Berghahn Books.

Usher, Phillip John

2014 Quotidian Chiasmus in Montaigne: Arguing Impotence and Suicide. In Chiasmus and Culture. Boris Wiseman and Anthony Paul, eds. Pp. 148-160. Studies in Rhetoric and Culture, 6. Oxford: Berghahn Books.

Vanier, Alain

2014 Chiasm in Suspense in Psychoanalysis. In Chiasmus and Culture. Boris Wiseman and Anthony Paul, eds. Pp. 143-147. Studies in Rhetoric and Culture, 6. Oxford: Berghahn Books.

Varela, Francisco J., Evan T. Thompson, and Eleanor Rosch

1991 The Embodied Mind: Cognitive Science and Human Experience. Cambridge, MA: Massachusetts Institute of Technology Press.

Washburn, Dorothy K. ed.

2004 Embedded Symmetries: Natural and Cultural. Amerind Foundation New World Studies, 6. Albuquerque: University of New Mexico Press.

Washburn, Dorothy K., and Donald W. Crowe, eds.

1988 Symmetries of Culture: Theory and Practice of Plane Pattern Analysis. Seattle: University of Washington Press.

2004 Symmetry Comes of Age: The Role of Pattern in Culture. Seattle: University of Washington Press.

White, Andrew A.

2015 Chaos, Complexity, and a Revitalization of Four-Field Anthropology? Reviews in Anthropology 44(3):142-160.

Wiseman, Boris

2007 Lévi-Strauss, Anthropology and Aesthetics. Cambridge: Cambridge University Press.

2009 Chiastic Thought and Culture: A Reading of Claude Lévi-Strauss. In Culture And Rhetoric. Ivo Strecker, and Stephen Tyler, eds. Pp. 85-103. Studies in Rhetoric and Culture, 1. Oxford: Berghahn Books.

2014 Chiasmus, Mythical Creation, and H. C. Andersen's "The Shadow." In Chiasmus and Culture. Boris Wiseman and Anthony Paul, eds. Pp. 219-238. Studies in Rhetoric and Culture, 6. Oxford: Berghahn Books.

Wiseman, Boris, and Anthony Paul, eds.

2014 Chiasmus and Culture. Studies in Rhetoric and Culture, 6. Oxford: Berghahn Books. 


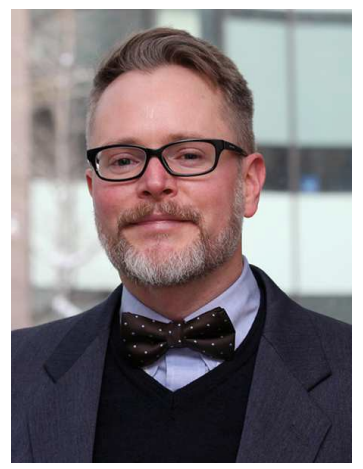

JAMIN PELKEY is an assistant professor of Linguistic Anthropology in the Department of Languages, Literatures and Cultures at Ryerson University, Toronto, Canada. Currently editor of Semiotics (Philosophy Documentation Center), Jamin researches questions at the intersections of sociohistorical linguistics, philosophy of language, cognitive semiotics, and embodied cognition. His ethnolinguistic field research on the Phula languages of Yunnan, China, is detailed in Dialectology as Dialectic (DeGruyter). Current book projects include Sociohistorical Linguistics in Southeast Asia (Brill) and The Semiotics of X (Bloomsbury Academic). 